\title{
Effect of Simulation-based Learning on Knowledge and Practice Regarding Hemodialysis Catheter Exit Site Care
}

\author{
Sariga J Theresa ${ }^{1}$, Reena Mathew ${ }^{2}$
}

\begin{abstract}
Background: Hemodialysis remains the most frequently used renal replacement modality across the globe. Vascular access needed to provide hemodialysis falls under two main categories that are short term and long term. Tunneled, cuffed central venous catheters are used extensively throughout the hemodialysis patient population as permanent arteriovenous access.

Objective: The objective of the study was to assess the effect of simulation-based learning as an effective learning strategy on knowledge and practices regarding hemodialysis catheter exit site care among dialysis technician students.

Materials and methods: Quantitative pre-experimental one-group pretest and posttest designs were adopted for the study. The purposive sampling technique was used to collect the data from 44 dialysis technician students.

Results: Most of the samples $(36,82 \%)$ had good knowledge, and most of the subjects $(37,84 \%)$ had a satisfactory practicing level after the intervention. There was a significant difference between knowledge and practice scores before and after the educational program $\left(p=0.001{ }^{*}\right)$. Conclusion: The study concluded that the intervention effectively improves the dialysis technicians as students' knowledge and practice regarding hemodialysis catheter exit site care as well as student satisfaction and self-confidence of simulation-based learning.

Keywords: Hemodialysis, Dialysis technician students, Knowledge, Practice, Simulation-based learning.

Pondicherry Journal of Nursing (2021): 10.5005/jp-journals-10084-13121
\end{abstract}

\section{INTRODUCTION}

Catheter-related bloodstream infection (CRBSI) is a common form of nosocomial infection that may be avoided. An infectious complication associated with their central venous catheter affects $5-26 \%$ of the patients. In the United States, an estimated 15 million catheter-days are spent in intensive care units (ICUs), with over 80,000 ICU patients developing a CRBSI each year at a rate of 1.2-5.2 infections per 1,000 catheter-days, leading to up to 28,000 fatalities and more extended hospital and ICU stay.

The Centers for Disease Control and Prevention (CDC) released guidelines for avoiding CRBSIs, which have become the gold standard for all central venous catheters (CVC) care recommendations. ${ }^{2}$ Hand hygiene, maximum sterile staff protective equipment, chlorhexidine for skin preparation, catheter site dressing regimens, and particular catheter insertion locations are all recommended in the guidelines. These criteria have been confirmed in several trials as effective in preventing CRBSIs. ${ }^{3}$

Educators have used innovative techniques for theoreticalpractical education in the 21st century, and simulation is a practical educational approach. It allows for the development of information, talents, and decision-making skills necessary for clinical practice. ${ }^{4}$ It is also a safe practice method in the healthcare profession. Simulation allows essential aspects of the real clinical field to be replicated in a learning environment, with the added benefit of repeatability as many times as needed, enhancing the learning process and supporting students' autonomy, independence, and self-confidence in relation to patient care practices. ${ }^{5}$

\section{Need to Conduct the Research}

Patients receiving hemodialysis with central venous catheters had difficulties and/or complications such as catheter infection, hematoma, pneumothorax, infection, thrombosis of the subclavian vein, and insufficient flow, according to clinical experience and
${ }^{1}$ Department of Medical-Surgical Nursing, Pushpagiri College of Nursing, Pathanamthitta, Kerala, India

${ }^{2}$ Department of Dialysis Technology, Pushpagiri College of Allied Health Sciences, Pathanamthitta, Kerala, India

Corresponding Author: Sariga J Theresa, Department of MedicalSurgical Nursing, Pushpagiri College of Nursing, Pathanamthitta, Kerala, India, Phone: +91 9048521224, e-mail: sarigatheresa@gmail.com

How to cite this article: Theresa SJ, Mathew R. Effect of Simulationbased Learning on Knowledge and Practice Regarding Hemodialysis Catheter Exit Site Care. Pon J Nurs 2021;14(4):77-79.

Source of support: Nil

Conflict of interest: None

observation in hemodialysis units. ${ }^{6}$ Some of these problems/ complications can be avoided by utilizing intense and coordinated treatments to save their lives. As a result, the purpose of this study was to examine dialysis technician students' knowledge and behaviors regarding hemodialysis catheter exit site care.

\section{Овj ective}

The objective of the study was to assess the effectiveness of simulation-based learning on students' knowledge and practices regarding hemodialysis catheter exit site care among dialysis patients.

\section{Materials and Methods}

A prospective qualitative research approach was adopted to conduct the study. Pre-experimental one-group pretest and posttest designs were used to implement the simulation-based learning intervention in the study. The nonprobability purposive sampling technique was used to collect the data from 44 dialysis 
technician students who all are eligible for inclusion criteria at Pathanamthitta District, Kerala, India. The demographic pro forma were prepared by researchers' properties including age, gender, year of study, and previous training information. A total of five research instruments were used to collect the data such as demographic pro forma: (a) Catheter Exit Site Care before Hemodialysis Checklist, (b) Hemodialysis Catheter Exit Site Audit Tool (CDC), (c) Structured Knowledge Questionnaire on Hemodialysis Catheter Exit Site Care, (d) Simulation Design Scale (SDC), and (e) Student Satisfaction and Self-confidence in Learning Scale.

The research instrument was validated with experts in the field of medical surgical nursing department and nephrology department. The reliability of the tool was assessed and reported by the primary authors. The Institutional Ethical Clearance (IEC) permission was obtained for the study. The objectives of the study were explained to all the samples. The data were analyzed using SPSS version 20. Frequency, percentage, mean, and standard deviation were included in the descriptive statistics and inferential statistics were used to determine the association between the variables.

\section{Data Collection Process}

The data were collected from five phases in total. Phase I: The investigators observed the practice of catheter exit site care before and after hemodialysis among students. The students were not informed that their practice was observed. Phase II: The investigator collected the baseline data. The knowledge of the students was assessed using a structured questionnaire. Phase III: Investigator demonstrated the procedure of hemodialysis catheter exit site dressing technique on a full body mannequin followed by a return demonstration by each student on the mannequin which was assessed using Hemodialysis Catheter Care Exit Site Checklist by investigators (two observers). Phase IV: A debriefing session was conducted to review each student's performance. After the completion of simulation-based training, each student completed the Simulation Design Scale and Student satisfaction and Self-confidence scale. Phase V: Postknowledge and practice of each student was assessed in the dialysis unit using the observation checklist and structured knowledge questionnaire.

\section{ResUlts}

\section{Objective 1: To Assess the Level of Knowledge and Practice Regarding Hemodialysis Catheter Exit Site Care}

Figure 1 reveals that majority of the samples $(26,59.1 \%)$ had average knowledge before the intervention and, after the intervention, most of the samples $(36,82 \%)$ had good knowledge.

Figure 2 reveals that majority of the sample $(31,70.5 \%)$ had an unsatisfactory practice level before the intervention and, after the intervention, most of the samples $(36,82 \%)$ had satisfactory practice levels.

\section{Objective 2: To Assess the Effectiveness of Simulation- based Learning on Knowledge and Practice Regarding Hemodialysis Catheter Exit Site Care}

Inferential statistics (paired sample $t$-test) were used to check the effectiveness of simulation-based learning intervention. Table 1 shows that there is a statistically significant difference between pretest mean scores and posttest mean scores of

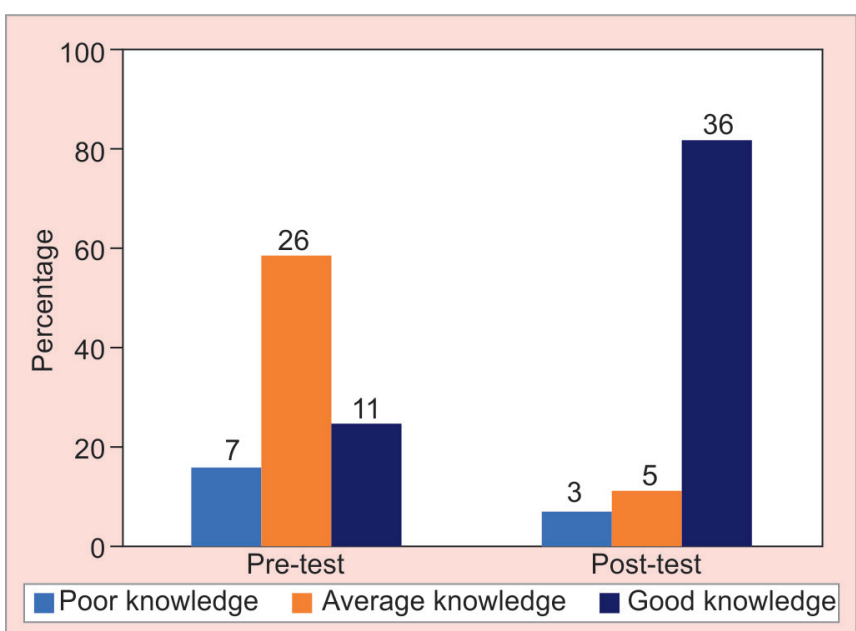

Fig. 1: Level of knowledge regarding hemodialysis catheter exit site care among dialysis technician students

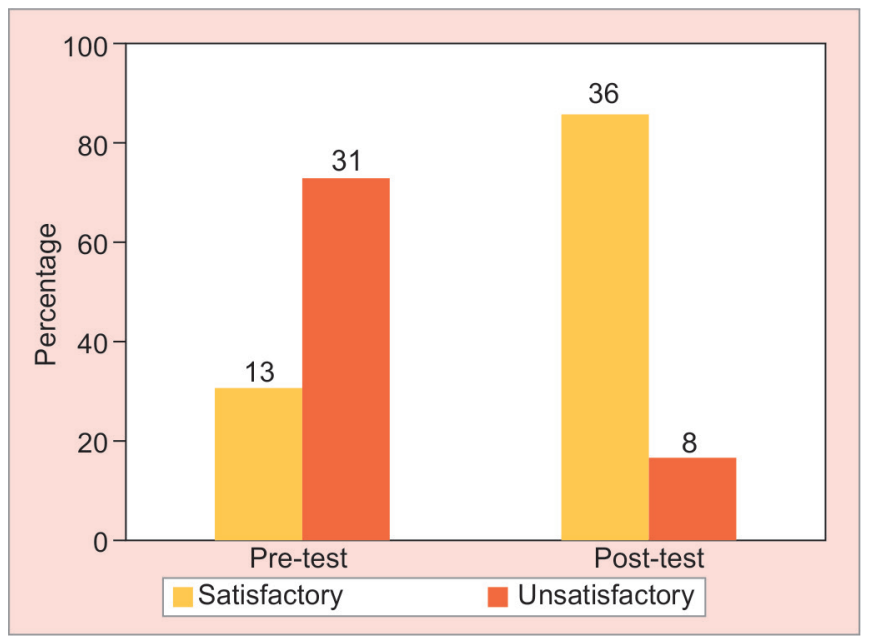

Fig. 2: Level of practice regarding hemodialysis catheter exit site care among dialysis technician students

Table 1: Mean and standard deviation of simulation-based learning intervention in experimental and control groups

\begin{tabular}{lcccc}
\hline Knowledge score & Mean & Std. deviation & tstatistic & pvalue \\
\hline Before intervention & 11.82 & 2.21 & -23.14 & $<0.001^{*}$ \\
After intervention & 16.89 & 1.78 & & \\
\hline Practice score & Mean & Std. deviation & tstatistic & pvalue \\
\hline Before intervention & 20.84 & 3.04 & \multirow{2}{*}{-17.10} & $<0.001^{*}$ \\
After intervention & 26.09 & 2.12 & & \\
\hline
\end{tabular}

knowledge and practice ( $p<0.001)$. Hence, it is concluded that the intervention effectively increases the knowledge and practice scores regarding hemodialysis catheter exit site care among the dialysis technician students.

Table 1 reveals that there is a statistically significant difference between pretest and posttest mean scores of knowledge $(11.82 \pm 2.21$ to $16.89 \pm 1.78, p<0.001)$ and practice $(20.84 \pm 3.04$ to $26.09 \pm 2.12, p<0.001)$ standard deviation hemodialysis catheter exit site care. 


\section{Objective 3: To Assess the Association between Knowledge and Practice Scores with Selected Demographic Variables}

\section{Association with the Level of Knowledge}

We have used a Chi-square formula to assess the statistical association between the two categorical variables. The study found that there is a significant association between the levels of knowledge and year of study $\left(p=0.002^{*}\right)$, received education $\left(p=0.002^{*}\right)$, and clinical training $\left(p=0.002^{*}\right)$. There was no statistically significant association found between the age of the participants $(p=0.10)$ and the gender $(p=0.22)$. The study concluded that there is a significant statistical association found between knowledge score and selected demographic variables.

\section{Association with the Level of Practice}

We have used a Chi-square formula to assess the statistical association between the two categorical variables. The study finds that there is a significant association between the levels of practice and year of study $\left(p=0.002^{*}\right)$, received education $\left(p=0.002^{*}\right)$, and clinical training $\left(p=0.002^{*}\right)$. There was no statistically significant association found between the age of the participants $(p=0.26)$ and gender $(p=0.10)$. The study concluded a significant statistical association between the levels of practice and selected demographic variables.

\section{Discussion}

The present study reported that there is a statistically significant difference between pretest and posttest mean scores of knowledge $(11.82 \pm 2.21$ to $16.89 \pm 1.78, p<0.001)$ and practice $(20.84 \pm 3.04$ to $26.09 \pm 2.12, p<0.001)$ standard deviation hemodialysis catheter exits site care. This is supported by an experimental study in Kuwait; it is reported that significant improvements in all aspects and total mean scores of knowledge $(p=0.001)$ and practice ( $p=0.001)$ regarding the CVC care and maintenance were observed among participants in the postintervention phase following implementation of the educational program. ${ }^{7}$

The study found that there is a significant association between the levels of knowledge and year of study $\left(p=0.002^{*}\right)$, received education $\left(p=0.002^{*}\right)$, and clinical training $\left(p=0.002^{*}\right)$. The study finds that there is a significant association between the levels of practice and year of study $\left(p=0.002^{*}\right)$, received education $\left(p=0.002^{*}\right)$, and clinical training $\left(p=0.002^{*}\right)$. The present study findings were supported by an experimental study conducted in Egypt, and the study revealed that there is a significant association found between posttest knowledge level and practice level with selected demographic variables such as education $(p<0.001)$, years of experience ( $p=0.001)$, and attended intensive training sessions $(p<0.001)^{8}$

In peritoneal dialysis patients, proper exit site care is critical for preventing catheter infections. Good hand cleanliness and aseptic procedures should be stressed to avoid contact contamination, regardless of whether the patient is receiving early or chronic treatment. ${ }^{3}$ In addition to the aseptic methods, physicians may prescribe medicines to help prevent bacterial infections. Research studies have proved that nursing personnel and technicians are critical in reducing infectious problems. Following the insertion of a central venous dialysis catheter, the nurse carries out connection/ disconnection procedures and insertion-site dressing procedures. ${ }^{4}$

\section{ConCLusion}

This study concluded that simulation-based learning has a significant impact on knowledge and practice regarding hemodialysis catheter exit site care among the dialysis technician students. The healthcare professionals and teaching faculty from healthcare institutions will play an essential role in improving students' knowledge and promoting best practices to give excellent care to the patient and avoid hospital-acquired infections and other possible infections while given care to hemodialysis patients.

\section{ACKNOWLEDGMENTS}

The authors acknowledge that this is an original research work carried out by a principal investigator with subject interest. This manuscript has not been published elsewhere or submitted to any other journals for publication.

\section{Ethical Consideration}

The investigator obtained permission from the Institution Research Board (IRB), hospital authority and written informed consent was obtained from the students.

\section{Confidentiality}

The research has maintained confidentiality throughout the study to protect the rights of the study subjects. This study did not collect the names, addresses, and any other personal details from the participants.

Asterisk $(*)$ refers to that there is a significant difference or association between mentioned variables.

\section{References}

1. Rupam Gahlot CN. Catheter-related bloodstream infections. Int Crit IIIn Inj Sci 2014;4(2):162. DOI: 10.4103/2229-5151.134184.

2. Astle CM. Hemodialysis catheter exit site care. Contrib Nephrol 2007;154:84-96. DOI: 10.1159/000096816.

3. Vachharajani TJ. Dialysis Catheter: "Love-Hate Relationship." Indian J Nephrol 2018;28(3):185-186. DOI: 10.4103/ijn.IJN_157_17.

4. Barsuk JH, McGaghie WC, Cohen ER, O'Leary KJ, Wayne DB. Simulation-based mastery learning reduces complications during central venous catheter insertion in a medical intensive care unit.* Crit Care Med 2009;37(10):2697-2701. PMID: 19885989.

5. Lateef F. Simulation-based learning: just like the real thing. J Emerg Trauma Shock 2010;3(4):348. DOI: 10.4103/0974-2700.70743.

6. Gerolemou L, Fidellaga A, Rose K, Cooper S, Venturanza M, Aqeel A, et al. Simulation-based training for nurses in sterile techniques during central vein catheterization. Am J Crit Care Off Publ Am Assoc CritCare Nurses 2014;23(1):40-48. DOI: 10.4037/ajcc2014860.

7. Abdo NM, Ramadan MA, Tosson MM, Al-Fadhli MA. Effectiveness of an educational program on knowledge and practices regarding care of central venous catheters among dialysis nurses. Egypt J Commun Med 2020;38(1):1-11. DOI: 10.21608/ejcm.2020.68615.

8. Bayoumi MH, Mahmoud NF. Effect of education program on nurses' knowledge and practice regarding care of central venous line in pediatric hemodialysis: evidence-based practice guidelines. Egypt Nurs J 2017;14(2):87-99. DOI: 10.4103/ENJ.ENJ_16_17. 